\title{
Primary School Teachers' Perceptions Regarding ICT Usage And Equipment In Kuwait
}

Ghazwa Alharbi, Griffith University, Brisbane-Australia

\begin{abstract}
Education institutions around the world have seen rapid advances in ICT (Information Communication Technology) within the classroom since the mid 90's. Kuwait has realized the need for a high quality education system, and has seen huge increases in government funding for schools over the last 10 years. However, Kuwait's spending on technology and ICT has attracted little research regarding the impact it has had on students and teachers. For this reason, this study aimed to discover how useful ICT is within classes in Kuwait. The research used qualitative research to focus on 14 teachers from three different primary schools in Kuwait. The study focused on the amount of ICT that is used within Kuwaiti schools and the quality of ICT training provided for teachers. The study found that teachers lacked sufficient training in ICT usage as a teaching aid. Findings also revealed that programs provided by the primary schools in Kuwait were too basic and that further investment is required.
\end{abstract}

Keywords: Information Communication Technology; ICT; Kuwaiti Education; Kuwait

\section{INTRODUCTION}

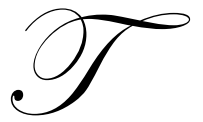

he use of ICT within education has increased significantly in the last 15 years. Kuwait has been at the forefront of technological advances in the Gulf States, and was the first country in the region to provide Internet use. The Kuwaiti government understands the need for high quality ICT, and the role it plays in modern education institutions. ICT has been introduced to all primary schools in Kuwait to various standards, but understanding the role it plays in schools is relatively unknown. Similarly, teacher levels of ICT competence is also yet to be documented.

The Ministry Of Education in Kuwait has taken up the challenge of modernising education by focusing on the use of technology. The Ministry is engaged in important projects to provide the necessary infrastructure and training for educational institutions with modern IT infrastructure and communication networks. (REF) Although much investment and time has been spent on ICT improvements, the task has not been carried out efficiently and the ICT in place is still basic (International Telecommunications Union, 2010)

The rapid changes in technology within Kuwait has had little input or feedback from teachers. For this reason, this study gathered teachers' expressions of satisfaction or displeasure regarding ICT use and ICT quality. Gathering this data is fundamental to justifying the funding used for ICT equipment by the ministry of education in Kuwait.

\subsection{Statement of the problem}

Kuwait educational institutes have been attempting to incorporate ICT as a teaching aid into classrooms with various degrees of success. ICT usage in the classroom depends entirely on the teacher and their levels of ICT competence. To date ICT usage in schools and teachers' competence are relatively unknown. 


\subsection{Significance of the study}

This study was one of only a few studies based in Kuwait regarding teacher perceptions and ICT usage. The qualitative methods used in this study offer an insight into Kuwaiti teachers' perceptions of how they teach classes and how they use ICT as a teaching aid within the class. Understanding teachers' perceptions of ICT can inform the creation of schemes or training for teachers to start implementing ICT usage in their classrooms on a daily basis. Data gathered from this study is also useful for Educational Institutions in terms of making further funding decisions.

\subsection{Research Questions}

The following questions were devised based on topics relating to ICT in Kuwait with little to no prior research available:

1. How does the quality of ICT equipment in Kuwait compare to other institutes around the world?

2. Do teachers believe the training delivered is comprehensive enough, and prepares students for the working world?

3. Does ICT usage improve the quality of classes for students?

4. In what ways do teachers use ICT within the classroom?

\section{LITERATURE REVIEW}

Previous studies within Kuwait investigated ICT perceptions of teachers. Aldhafeeri, Almulla and Alraqas (2006) describe teacher perceptions with regard to the impact ICT has on students in Kuwait. They suggest that education in Kuwait is based on memorising and recalling information, which is an outdated method in modern education. Instead, these researchers argue that students need to be proactive within learning. ICT usage would increase student participation and would offer dynamic methods to engage the class.

Phelps and Maddison (2008) investigated teacher perceptions regarding ICT usage in classrooms in high school. The qualitative study involved interviews with 14 teachers, asking questions regarding age, years in teaching and types of ICT used in classes. The study found that ICT usage is independent of the teacher's age. This finding dismisses the idea that older teachers have not embraced ICT as easily as younger generations.

Donnerly, McGarr and O'Rilley (2010) explain that teachers can be categorised by thinking and teaching methods. The groups of teachers range from 'traditionalists' who refuse to adapt to modern technology, to the 'creative adapters' who embrace all modern teaching aids and incorporate them into their class. The researchers suggest methods to help traditionalist teachers' adoption of ICT in the classroom.

Delacruz (2004) investigates the creative use of ICT within the classroom and how ICT can be used to engage a class. The study found that ICT usage within the classroom is generally not being incorporated in engaging or creative applications. Instead, the easier to use and less time consuming ICT activities tend to be used. The author states that changes need to be made by school policy makers, as teachers are in support of change and wish to be included in change. Baylor and Richie (2002) expand on the idea of policy change. The researchers also state the importance of including teachers in policy making when regarding ICT in the classroom. Including teachers in the design of new policies would increase the use of ICT within the classroom, as teachers understand the gaps in their teaching methods which ICT could be useful.

Some studies have investigated child age, and ICT usage by teachers. The study by Higgins and Moseley (2001) examined students from a wide variety of age groups to examine the methods teachers use to engage them. The study found that ICT usage depends entirely on how teachers perceive the impact it has on a class, regardless of training or courses they have received.

Challenging issues which emerge when researching ICT usage are described by Cox and Marshall (2007). They state that as ICT usage within classrooms varies significantly so it is difficult to state the impact that ICT has 
on students. Also, they suggest that engaging students can be achieved using various methods, as students learn in different ways. Using ICT directly is better for some students, while using interactive whiteboards is better for others. Therefore, Cox and Marshall (2007) make the point that stating one method is better than the other is not possible.

Pelgrum and Voogt (2009) investigated the differences in ICT in schools around the world. The study described how schools teach mathematics, and how often teachers use ICT per week. The implementation of ICT within lesser developed countries was surprising with some less developed countries using ICT to a far greater extent than developed countries like Japan or France.

ICT has a definite future in school classrooms, however according to literature Kuwait appears to be left trailing by western schools. Aldhafeeri, Almulla and Alraqas (2006) suggested several years ago that Kuwait schools focused on repetition and memorizing, which is an area which the current research aimed to re-evaluate. The study aimed to portray the perceptions and satisfaction teachers have in Kuwait, and understand the different attitudes teachers having depending on age and gender, similar to the study of Donnerly, McGarr and O'Rilley (2010). Previous studies in Kuwait have had little research based on teacher perceptions of ICT, which is the primary reason for the current study.

\section{METHOD}

The primary method of analysis for this research was through interviews. Participants were chosen at random, but had to meet several criteria in order to ensure results were unbiased and accurate. The participants were selected from three primary schools and were from a variety of different subject disciplines.

Interviews were arranged through phone calls to each of the schools involved. The research asked if staff would be interested in participating in a Skype interview. Schools replied with skype details of the participants interested, and which subject the teacher represented.

Each interview lasted approximately 20 to 30 minutes; interviews were carried out using Skype and were recorded for later analysis. Interviews were recorded in Arabic due to some teachers having difficulty communicating in English. Interviews were later translated into English for use within the study.

\subsection{Study Participants}

The Interview participants were from three high school institutions in Kuwait, and included 14 teachers in total from different subject areas. The subjects were:

- $\quad$ Science (five interviewees)

- $\quad$ Mathematics (three interviewees)

- $\quad$ Geography (two interviewees)

- $\quad$ English (two interviewees)

- $\quad$ Art/Design (two interviewees)

Teachers involved in the interviews had to have been in their current school for the past two years. Participants had to have access to ICT within their classroom. Participants were assured of complete anonymity in any responses they gave within the interviews. The interviewees were to be no older than 40 , however the age of the participant would not be displayed within the findings. Participants' identities were not disclosed within the interviews, including the schools they worked for.

\subsection{Data analysis}

The interviews were analysed using content analysis which was introduced by Williamson and Bow (2002). 
- $\quad$ The data collected from the interviews were then divided into different categories such as; How many positive and negatives occurred and any words that were frequently used.

- To observe trends regarding the words used in responses. After all the data was analysed it was then divided into the correct categories.

- Demographic questions were used to prove whether or not age, gender or years of experience had changed the findings stated previously.

Table 1:

Participant interview data

\begin{tabular}{|c|c|c|c|c|}
\hline Participant & Date & Subject & Experience (years) & Duration (minutes) \\
\hline 1 & $18-$ Sep-11 & Science & 4 & 21 \\
\hline 2 & $18-$ Sep-11 & Maths & 6 & 28 \\
\hline 3 & $19-$ Sep-11 & Science & 12 & 25 \\
\hline 4 & $19-$ Sep-11 & Science & 8 & 25 \\
\hline 5 & $22-$ Sep-11 & English & 5 & 22 \\
\hline 6 & $22-$ Sep-11 & Art & 11 & 25 \\
\hline 7 & $25-$ Sep-11 & Geography & 10 & 22 \\
\hline 8 & $25-$ Sep-11 & Science & 4 & 25 \\
\hline 9 & $25-$ Sep-11 & Maths & 5 & 26 \\
\hline 10 & $25-$ Sep-11 & Geography & 7 & 28 \\
\hline 11 & $26-$ Sep-11 & Maths & 9 & 21 \\
\hline 12 & $26-$ Sep-11 & Art & 7 & 23 \\
\hline 13 & $27-$ Sep-11 & English & 6 & 11 \\
\hline 14 & $27-$ Sep-11 & Science & & \\
\hline
\end{tabular}

\section{INTERVIEW FINDINGS}

Findings from the interviews uncovered several areas of discussion in support of as well as against the quality and usage of ICT within Kuwait schools. The 68 textual comments from the 14 interviewees were analysed, and the key points from each interview question were selected either as positive or negative. The most obvious theme and suggestion was that although the quality of equipment in the schools is good, the uses it has within a teaching environment are relatively unknown to teachers. The interviewees stated they had little to no training in using ICT, and use it either from self learning or trial and error over a period of time. See table 1 for participant information for the following interview quotes.

\subsection{How often do you use ICT in your classes, if yes for what purpose?}

Teachers stated that the use of ICT is limited to very few programs and the use of presentations seemed to predominate. Showing the class videos was another use for the projector systems, but none of the teachers explained any more uses other than very basic ICT skills. The majority of teachers explained they used ICT infrequently, approximately once per week.

I use ICT about once per week, normally I use a PowerPoint presentation relating to a subject I am delivering to the class. I use PowerPoint as I think some of the students prefer something engaging from time to time, but other than this I don't use it as a direct teaching aid. I use YouTube to show videos which I think support or are educational in a field I'm trying to explain with words alone. YouTube is good but my ICT skills are limited to these areas. (Participant 8)

In my class I have attempted to use ICT in the past, but I found it was not of much use to me. The PowerPoint presentations I created took quite some time to make, and when I attempted to use them the projector was not correctly calibrated with my workstation, meaning the class became restless while I attempted to fix the problem. After a few occasions I stopped using PowerPoint presentations and spent more time trying to engage the class in practical ways. (Participant 14) 
I use PowerPoint and the internet for diagrams and engaging ways to describe rather mundane science topics. The internet is a useful tool as I can show the class almost anything. However there are very few science programs installed on the network, meaning my usage is limited to PowerPoint and the internet. To be honest I don't know how to use anything else as I have not had any training since I have been here. I use videos for the students who struggle to listen to me talking for any long periods of time. My usage is just self taught and the websites I use are from friends or colleague recommendations. (Participant 10)

\subsection{What do you think about the quality of the ICT equipment provided by the school?}

Almost all the responses regarding the quality and quantity of ICT equipment available was positive. The majority of teachers stated that the ICT equipment was new and of high standard. However some of the teachers claimed that the programs installed were very basic and generic.

The ICT equipment provided by the school is high quality and has been installed in the last year. Students use the workstations well and I can help students with any issues they have whilst they work. It saves a lot of time using ICT to teach students which means they absorb more information in the same time. The mathematics puzzles installed on the computers are fun for the students and give the students a competitive drive to be the best, which is surprising for me as students had little interest in mathematics prior to the ICT being installed. (Participant 2)

The equipment is fantastic and was installed last year; the students were also very impressed with the quality and size of the monitors. The students are normally excited when I say we will be using the computers in today's lesson, as it gives them some freedom and allows them to think independently. The new printer I have installed in my class is very fast and I have had no problems with it, unlike the old printer I had. The students require very little instruction when using the computers as most of them are highly competent in computer usage, and the fact the computers are of high quality means we have no breakages or problems when the students get to use them. (Participant 3)

I like the new computers in the school and they certainly look impressive. However the programs we use have not progressed since the first computers were installed many years ago. The students are still using only word processors, PowerPoint, the internet and Excel, just the most modern versions. I would like the school to install some teaching programs or interactive learning packages to really engage the students when they use the computers. Most students now use the computer to do some basic research using Google, and spend the rest of their time talking or waiting for further instruction after they complete their tasks. (Participant 4)

\subsection{Do you feel that using ICT improves students' learning experience, if yes in which way?}

The idea that students' learning experience is improved was supported by teachers, as they felt ICT engaged the children and allowed them freedom to learn, letting the creative side of a child flourish. The responses to this question were positive.

Yes I feel the students benefit from using the ICT if the classes are well structured and planned. Using ICT alone does not, so the lessons have to get students thinking alone and challenging, such as research topics. I have noticed that if you allow them to think alone and give them enough information to succeed, they are well motivated and produce some remarkably high quality work. (Participant 5)

I think it is productive yes, and breaks the time into more manageable sections, so students don't become restless and tired of writing by hand the entire lesson. Using ICT is good for students as it allows them space and for them to feel like they are independent, which empowers them and class behavior normally improves as a result. Of course if I don't monitor them closely they will try and play games or watch cartoons, but thankfully the computer technicians have blocked most of their favorite websites. I feel that students absorb information without realizing whilst using computers, which is a very positive impact. (Participant 1)

Using ICT for teaching mathematics has helped students' concentration levels and behavior in class. Many of the students find maths tiresome and usually halfway through the lesson bad behavior occurs. Changing to computers 
usually improves this behavior and can help for the students learning to continue into the second half of the lesson. Playing mathematics games is fun for the students, and thankfully the games are challenging and worthwhile in playing, but I use them as a reward for hard work during the lesson. The students use the games for roughly 20 minutes if they complete their class work on time. (Participant 11)

\subsection{Do you feel the ICT skills of students needs to improve, or are they at an acceptable level to succeed in the future?}

Teachers all responded extremely positively regarding the level of ICT competence with their classes. The main response was that students who have ICT available at home are highly competent. Teachers suggested that students use programs well, and are able to research independently using the internet.

The school understands the importance of ICT for future careers that the children will have, therefore improving ICT skills is highly important. I have found that almost all of the students I teach have home computers or laptops and are competent users of ICT. Only a limited number of students have poor skills and that is due to no computers being available for them at home. The students with no computers at home are far behind the skills of students with computers, however they learn quickly and I will try to give more time to these students. In general though I am confident the ICT skills of the students are good and they will take these skills with them into the future. (Participant 13)

Yes my students really are confident and comfortable using ICT, and I have noticed improvements over the years as more and more young children use ICT from a younger age than maybe 10 years ago. My students now all have $P C$ 's at home and know how to use all the main programs on computers. I am confident that the current generation of students will have the highest ICT skills possible by the time they leave education and go into the working world. (Participant 7)

My students love to use ICT and become excited and happy when I say that we will use the computers in today's lesson. I have noticed how comfortable they are when using the computer and can work very quickly and efficiently even at a relatively young age. I have no issues with the ICT skills of my students and this makes teaching students very simple when we use the computers, as they already know much of the information I am teaching. (Participant 12)

4.5. What further improvements or changes should schools implement to improve the ICT skills and quality of classes in Kuwait?

Teachers had several suggestions regarding possible changes in ICT skills and equipment, with several responses relating to the amount of projectors available at the school. However the overwhelming response focused on ICT usage training, specifically how to teach a class using ICT. Teachers claimed they had no training in this area and desperately required it.

I would suggest the school provides teachers with laptops on loan or on a permanent basis, as the school expects teachers to have their own laptops. The school also has only limited amounts of projectors which have to be booked in advance, so if I fail to book the projector in time I have to change my lesson plan. Each classroom should have a projector as I am sure many western schools would have this feature. (Participant 3 )

The school should defiantly invest in some ICT training courses for using ICT as a teaching aid. I don't really know what use ICT has other than YouTube and PowerPoint, but I'm sure there are a wide variety of programs we could be using if we had the correct training. Interactive whiteboards would be a useful addition to the classroom so save time when I have to handwrite any classes I am delivering. If we had interactive whiteboards I could load the lesson plan directly from the computer for the students to read and take notes, perhaps while I am preparing the next task or marking assignments. (Participant 8)

The ministry of education has invested heavily in ICT in the last few years, and all the workstations in the school are running the latest programs. However the training provided in new technologies has not been available and my 
knowledge of ICT has not improved or changed for many years. I am still using the same methods and routines for computer use as I was about 7-8 years ago. I'm sure we could be using ICT better but I would like to know how, that is my main request. (Participant 6 )

\section{DISCUSSION}

According to the interview results, several topics became apparent based on similar themes reoccurring in many interviews. Responses from teachers were both positive and negative. The interviewees' response to how often they used ICT within the class was inconclusive, most stated they either used ICT infrequently or once per week. There was a lack of structure regarding how often they used ICT, it was dependent on the teachers feeling on that particular day or if equipment was available. The years of experience a teacher had made no impact on how often they used ICT within the class. This could be due to the fact that none of the teachers involved in the study were over the age of 40 . The use of ICT by teachers within the class was predominantly for slide shows using PowerPoint, or YouTube videos to help reinforce teachings. The use of videos seemed to be to help students who learn better through visual representation rather than verbal commands.

Teachers responded extremely positively regarding the IT workstations which were available throughout the three schools. This indicated that there has been investment in IT in the last few years. The workstation quality is of a high standard throughout the schools, and the staff has no issues with the quantity or quality of IT workstations. The quality of the computers is clearly of high quality, which is supported by the fact the Ministry Of Education in Kuwait signed a Memorandum of Understanding (MoU) with global computer giant Hewlett Packard (HP), in which schools are supplied with new technology for the duration of the agreement by HP.

Based on the results of question three, the teachers are positive about using ICT as a learning aid within the classroom. Teachers have a clear understanding of how to use computer workstations to keep students motivated and focused on the lesson. Teachers stated that allowing children some freedom in what they do whilst on the computers, often encouraged self-motivation and produced higher quality work. Self -motivated student behavior is normally very good, as students like to feel they are being treated in a mature manner, not as a child, which the following statement supports:

Using ICT is good for students as it allows them space and for them to feel like they are independent, which empowers them and class behavior normally improves as a result (Participant 1).

The high ICT skills of students received the strongest support from teachers throughout the interviews. Teachers claimed that students had very high levels of ICT competency for their age, which the vast majority stated was due to the availability of home computers. The current generation of students has developed their skills at a greater rate than any other generation, due to the internet and home computers had been well established by the time they were born or at a young age. Teachers had no concerns with students ICT skills, other than students who had no access to home computers, which was a fraction of the students from the three schools.

Teacher suggestions focused primarily on improving ICT training for staff, and how to use ICT as a teaching aid. The majority of teachers claimed they had little to no training at various stages of the interviews. Most claimed they used ICT from self learning. The ICT skills of some of the teachers are lacking in comparison with other teachers, and the use of the projector equipment is for basic presentations and very little else.

Although computers provided by the school are of high quality and new, the programs installed on the computers are very basic, and the computers have very few educational or teaching packages. Teachers recommended the schools should invest in specific subject packages, such as interactive games or design packages for students to use to make lessons enjoyable as well as educational.

Teachers suggested that schools should invest in projectors at some of the schools, which indicated that the school has a lack of projector equipment, or the equipment is difficult to arrange or book for classes. Teachers stated that each classroom should be equipped with a projector if a projector is deemed useful for the subject being taught. Interactive whiteboards were the final suggestion from a few interviewees, although teachers would prefer a projector system rather than any other piece of equipment. 


\section{CONCLUSION}

This study investigated teacher perceptions regarding ICT usage in Kuwaiti primary schools, and covered four areas of interest. The study found that Kuwaiti schools are equipped with high quality and modern computer workstations, provided by industry leading companies; therefore the quality is on par with any western country primary school. The interviews uncovered that students ICT skills are exemplary, and the teachers have no concerns about the ability for students to perform an array of tasks using ICT. This finding could be due to the current ease of access to high speed home computers.

Teachers understand the importance of ICT in the modern classroom, and allow students to use workstations from time to time; however the use of projectors is limited in some cases due to a lack of equipment provided.

Teachers' use of ICT within the classroom is limited for two reasons, a lack of equipment provided by schools (projectors, interactive whiteboards, and laptops) and a lack of training in how to structure classes around the use of ICT. This lack of training could be seen as the main point which participants wanted to portray during the interviews.

This study recommends further training to be provided to teachers focused on ICT usage for teaching. This study also recommends training focused on using projectors and interactive whiteboards for teaching. Training would allow teachers to provide students with a new and interactive method of teaching which students would find interesting and engaging.

Future research could be subject specific with regards to teacher perceptions, to understand the ICT equipment and needs for various subjects. Also a future study could follow up on the current study's findings, if teachers were given training in using ICT for teaching, to find how often teachers use ICT and how their lessons have changed as a result of this.

\section{AUTHOR INFORMATION}

Mrs. Ghazwa Alharbi, is a Kuwaiti national currently qualified as a master of general education, and has study in Griffith University, Australia. She has previous experience in the field of education from her work in Kuwait as a kindergarten teacher (2002-2005) for the ministry of Education Kuwait. Her fields of interest revolve around the use of ICT in educational institutions, and the perceptions of teachers at various schooling levels. Previous research has focused on school violence and parental influences on child behavior. E-mail: Umh130@ hotmail.com

\section{REFERENCES}

1. Aldhafeeri, F., \& Almulla, M. (2006). Teachers' expectations of the impact of E-learning on kuwait's public education system. Social Behavior and Personality, 34(6), 711-728.

2. Cox, M. J., \& Marshall, G. (2007). Effects of ICT: Do we know what we should know? Education and Information Technologies, 12(2), 59-70.

3. Delacruz, E. (2004). Teachers' working conditions and the unmet promise of technology. Studies in Art Education, 46(1), 6-19.

4. Higgins, S., \& Moseley, D. (2001). Teachers' thinking about information and communications technology and learning: Beliefs and outcomes. Teacher Development, 5(2), 191-210.

5. http://www.itu.int/ITUD/sis/newslog/2010/06/24/KuwaitAndSingaporeExpandOnICTForEducationAgreem ent.aspx

6. Pelgrum, W. J., \& Voogt, J. (2009). School and teacher factors associated with frequency of ICT use by mathematics teachers: Country comparisons. Education and Information Technologies, 14(4), 293-308.

7. Phelps, R., \& Maddison, C. (2008). ICT in the secondary visual arts classroom: A study of teachers' values, attitudes and beliefs. Australasian Journal of Educational Technology, 24(1), 1-14.

8. Williamson, K. \& Bow, A. (2002). Analysis of quantitative and qualitative data. In K. Williamson, Research methods for students and professionals: Information management and systems ( $2^{\text {nd }}$ ed., pp. 285303). Wagga Wagga, NSW: Centre for Information Studies, Charles Sturt University. 